\section{CT Role in the Assessment of Existence of Breast Cancerous Cells}

\author{
Mehnati P. ${ }^{1 \oplus}$, Jafari Tirtash M. ${ }^{2 *} \odot$, Ghavami M. ${ }^{3}$
}

\begin{abstract}
Background: Application of CT- scanning image information and radiation physical characteristics of the biomaterials are two measurable assays for presenting modified cells.

Objective: This study presented that CT number (HU) and linear attenuation coefficient contain useful information which can be determined during usual CT scanning for the prediction of breast cancerous cells existence based on hemoglobin concentration.

Material and Methods: This experimental study used breast phantom containing major and minor vessels with diameters of 10 and $5 \mathrm{~mm}$, respectively. The major vessels are filled by water, fat, hemoglobin $(\mathrm{Hb})$ as a normal and $4 \times$ concentration of hemoglobin $(4 \times \mathrm{Hb})$ as a cancerous breast cells, then scanned by single slice CT (GE, Hi Speed) $120 \mathrm{kVp}, 100 \mathrm{~mA}$ for the determination of linear attenuation coefficient $\left(\mu_{L}\right)$. Results: The CT numbers were for water $(-7$ to $+7 \mathrm{HU}), \mathrm{Hb}(22 \pm 6 \mathrm{HU})$ and $4 \times \mathrm{Hb}$ $(80 \pm 4 \mathrm{HU})$. The difference between $\mathrm{Hb}$ and $4 \times \mathrm{Hb}$ was significant $(p<0.000)$. Minimum $\mu_{L}$ was $0.1190 \pm 0.00680 \mathrm{~cm}^{-1}$ for fat and maximum was $0.1449 \pm 0.00794 \mathrm{~cm}^{-1}$ for $4 \times \mathrm{Hb}$.
\end{abstract}

Conclusion: The study of CT number and linear attenuation coefficient of different concentration of $\mathrm{Hb}$ provides a possibility for early predicting of breast cancerous cells existence $(4 \times \mathrm{Hb})$.

Citation: Mehnati P, Jafari Tirtash M, Ghavami M. CT Role in the Assessment of Existence of Breast Cancerous Cells. J Biomed Phys Eng. 2020;10(3):349-356. doi: 10.31661/jbpe.v0i0.384.

\section{Keywords}

Tomography, X-Ray Computed; HU Measurements; Blood; Body Fluids

\section{Introduction}

$\mathrm{T}$

he spectrum of X-ray beam contains higher and lower energy portions which is differently absorbed by the object and changes as it passes through it. Current CT systems correct this phenomenon called beam-hardening effective energy shift, using calibration data measured in specific phantoms and calculated with the specific function during the image reconstruction process. If beam-hardening correction is not sufficient, nonlinear artifacts such as shading and dark artifacts occur which might mimic diseases and lead to misdiagnosis $[1,2]$. Spectral computed tomography $(\mathrm{CT})$ measurements of X-ray attenuation are used as object additional information and determining its composition as well as discriminating among different materials [3]. CT number $(\mathrm{HU})$ provides a standard scheme for scaling the reconstructed attenuation coefficients in medical CT systems. CT numbers correlate to gray levels or gray shades when the volumetric dataset is rendered into
${ }^{1} \mathrm{PhD}$, Department of

Medical Physics, School

of Medicine, Tabriz

University of Medical Sci-

ences, Tabriz, Iran

${ }^{2} \mathrm{MSc}$ Student, Depart-

ment of Medical Physics,

School of Medicine Ta-

briz University of Medical

Sciences, Tabriz, Iran

${ }^{3} \mathrm{MD}$, Department of

Radiology, School of

Medicine, Tabriz Univer-

sity of Medical Sciences,

Tabriz, Iran

*Corresponding author: M. Jafari Tirtash

Department of Medical

Physics, School of Medi-

cine, Tabriz University of

Medical Sciences, Gol-

gasht street, Tabriz, Iran

E-mail: jafarimaede@

gmail.com

Received: 26 May 2015 Accepted: 19 June 2015 
images, which are displayed on a monitor (or printed) [4-6].

The probability that a photon would undergo an interaction while passing through a unit thickness of material is defined by the linear attenuation coefficient $(\mu)$, which has units of $\mathrm{cm}^{-1}$. The linear attenuation coefficient $\left(\mu_{L}\right)$ is dependent on the composition of the attenuating material and the photon energy. The intensity $I$, the exponential attenuation law states:

$$
I=I_{0} \cdot \exp ^{\left(-\mu_{L} x\right)}
$$

Where $I_{0}$ is the initial intensity of the incident beam, and $x$ is the thickness of material through which the beam passes.

Different concentrations of hemoglobin of blood can be used for determining the condition of normal or abnormal breast cells. In clinical CT images, blood is characterized and differentiated based on Hounsfield unit (HU) magnitudes and ranges [7-9]. In the Hounsfield scale, the radiodensity of measured materials can change with different amounts of tube current. The radiodensity of blood is known to be in the ranges of 40 and $60 \mathrm{HU}$, and the exact HU value depends mainly on the cellular content especially the concentration of hemoglobin [10]. Almost all study data referred to about normal hemoglobin but rare data showed concentrated hemoglobin HU in comparison with normal hemoglobin.

CT image data are dependent on the density of tissues and the beam energy, where each image pixel is assigned a Hounsfield unit (HU) $[11,12]$. These images are made up of pixels, which has a gray scale value from 1 (black) to 256 (white). This value corresponds to the amount of X-rays passing through the structure, and can be measured and expressed in Hounsfield units (HU). HU is directly related to $\mu_{L}$ at the effective energy of CT (ECT) scanner which are calibrated with reference to water. Accurate CT number measurements are relevant in several clinical applications, which rely on quantitative $\mathrm{HU}$ values for diagnosis.

In human body, the low atomic number ( $Z$ ) composition of the soft tissue causes dominant scattering. Since these factors are related to the density and composition of body tissues, it is crucial to have access to individual attenuation maps to account for the attenuation and scattering effects when high quantitative accuracy is desired. It requires accurate measurement of attenuation. In cancerous breast, changes on the concentration of blood hemoglobin are important signs for early detection.

This study quantifies the CT number (HU) and linear attenuation coefficient $\left(\mu_{L}\right)$ of different concentrations of hemoglobin and introduces their usefulness for presenting detailed information for the assessment of different conditions of breast especially prediction of cancerous breast cells.

\section{Material and Methods}

\section{Material Selection}

In experimental study a wide range of densities of materials which almost exist in breast tissue including water, milk, fat, Oxy or normal hemoglobin $(1 \times$ hemoglobin $)$ and deoxy or abnormal hemoglobin $(4 \times$ hemoglobin) were selected. Pomegranate juice (red color) is used for contrast purpose. Different concentrations of hemoglobin are used to simulate the normal and cancerous breast cells.

\section{Phantom Properties}

The breast phantom is made up of polyethylene with dimensions $5 \times 18.5 \times 12.5 \mathrm{~cm}^{3}$. The phantom contains two major $10 \mathrm{~mm}$ and $\mathrm{mi}$ nor $5 \mathrm{~mm}$ vessels. All above-mentioned materials were inserted into the main vessels in the breast phantom (Figure 1A).

\section{CT Scanning}

General Electric Hi Speed (GE, Hi Speed, USA) diagnostic X-ray CT scanner is used to estimate an average $\mathrm{HU}$ value over a number 
A

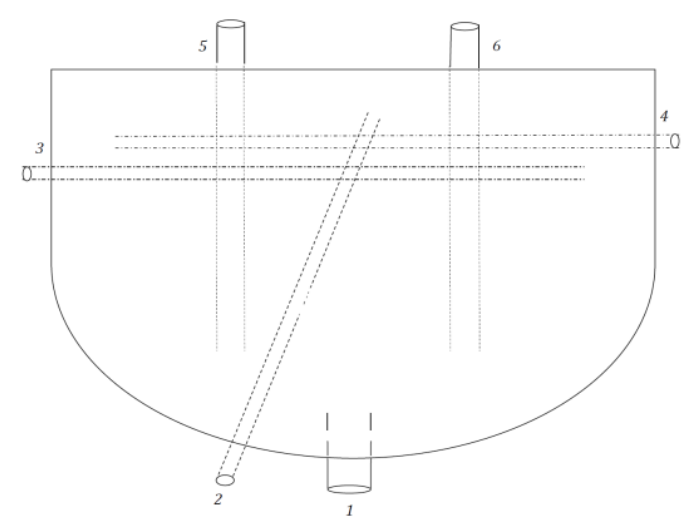

B

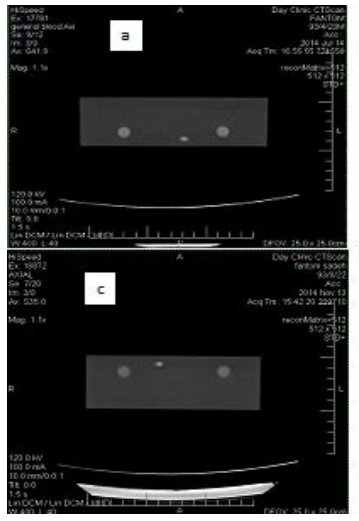

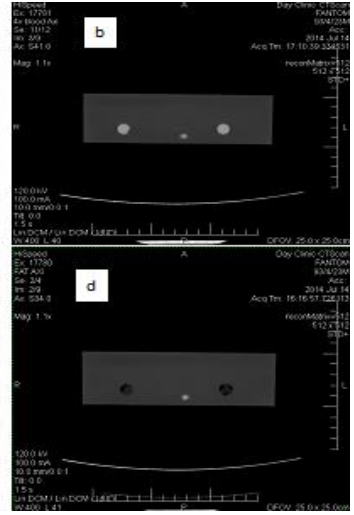

Figure 1: Part A: The breast phantom is made of polyethylene, organized within major and minor vessels as shown from number 2 to 6 . Number 1 is nipple, 2, 3 and 4 are minor vessels with $5 \mathrm{~mm}$ diameter, 5 and 6 are main vessels with $10 \mathrm{~mm}$ diameter. $\mathrm{Hb}$ and $4 \mathrm{xHb}$ inserted to major vessels. Part $\mathrm{B}$ : $\mathrm{CT}$ images showed different $\mathrm{HU}$ including $\mathrm{a}: \mathrm{Hb}, \mathrm{b}: 4 \times \mathrm{Hb}, \mathrm{c}$ : water, $\mathrm{d}$ : fat.

of slices at $120 \mathrm{kVp}, 150 \mathrm{mAs}, 9$ slices and one pitch. Spiral and axial scanning mode are used at $10 \mathrm{~mm}$ intervals.

One $\mathrm{cm}^{2}$ of region of interest (ROI) was selected on each image and an HU value determined within each ROI. Linear attenuation coefficients are calculated according to CT number values using standard definition:

$$
H U=\frac{\left(\mu_{\text {material }}-\mu_{\text {water }}\right)}{\left(\mu_{\text {water }}-\mu_{\text {air }}\right) \times 1000}
$$

Where $\mu_{\text {water }}$ and $\mu_{\text {air }}$ are the linear attenuation coefficients of water and air, respectively. This definition is for CT scanner calibrated with water reference. A change of one Hounsfield unit (HU) represents a change of $0.1 \%$ of the $\mu$ of water since the $\mu$ of air is nearly zero.

Data were analyzed by SPSS 16 software and compared by T-test statistically based on which a significance level was $\mathrm{p}<0.05$.

\section{Results}

The CT imaging of breast phantom contains water, fat, $\mathrm{Hb}$ and $4 \times \mathrm{Hb}$ which are inserted into main vessels are shown in Figure 1. Different radiodensity of experimental materials in CT imaging induced to diverse gray level which is displayed as an $\mathrm{HU}$ value on the monitor of CT.

The mean $\mu_{L}$ is calculated according to $\mathrm{HU}$ as presented in Table 1. The minimum value was for fat $(-100 \pm 10)$ and maximum was for $4 \times \mathrm{Hb}(80 \pm 4)$. The standard deviation in the HU estimate over the ROI was found to be as low as $10 \%$. A comparison of CT numbers showed that the color of water in pomegranate juice can change the CT number nearly seven times. The concentration of hemoglobin in $4 \times \mathrm{Hb}$ induces to change $\mathrm{CT}$ number nearly four times which is seen in abnormal or cancerous breast cells. The characterization of tumors in soft tissues included CT number in the range of 0 to $100 \mathrm{HU}$.

The linear attenuation coefficient was calculated for different tube potentials from 75 to $364 \mathrm{keV}$. As shown in Table 2, the mean CT number of water must be evaluated at 
Mehnati P., Jafari Tirtash M., Ghavami M.

Table 1: CT Number (HU) of experimented materials and SD mean \pm and Linear attenuation coefficients $\left(\mathrm{cm}^{-1}\right)$ are shown.

\begin{tabular}{cccc} 
Materials & CT Number & SD & $\boldsymbol{\mu}$ mean \\
\hline Water & 0 & 7 & 0.134 \\
\hline Pomegranate water & 44 & 4 & 0.140 \\
\hline Milk & 27 & 6 & 0.137 \\
\hline Fat & -100 & 10 & 0.119 \\
\hline $\mathrm{Hb}$ & 22 & 6 & 0.137 \\
\hline $4 \times \mathrm{Hb}$ & 80 & 4 & 0.145 \\
\hline Polyethylene (Phantom material) & -77 & 10 & 0.124
\end{tabular}

Table 2: The relation between linear attenuation coefficient $(\mu)$ and energy in the range of 75-364 keV

\begin{tabular}{cccccccc} 
Energy (Kev) & Water & Pomegranate water & Milk & Fat & Hb & $\mathbf{4 \times H b}$ & polyethylene \\
\hline $75-80$ & 0.160 & 0.167 & 0.164 & 0.14 & 0.164 & 0.172 & 0.147 \\
\hline 140 & 0.149 & 0.156 & 0.153 & 0.134 & 0.152 & 0.161 & 0.137 \\
\hline 160 & 0.138 & 0.144 & 0.141 & 0.124 & 0.141 & 0.149 & 0.127 \\
\hline 167 & 0.137 & 0.143 & 0.14 & 0.123 & 0.14 & 0.148 & 0.126 \\
\hline 170 & 0.135 & 0.141 & 0.139 & 0.122 & 0.138 & 0.146 & 0.125 \\
\hline 245 & 0.121 & 0.126 & 0.124 & 0.101 & 0.124 & 0.131 & 0.112 \\
\hline 364 & 0.099 & 0.103 & 0.102 & 0.089 & 0.101 & 0.107 & 0.091 \\
\hline Error & 0.007 & 0.008 & 0.007 & 0.007 & 0.008 & 0.008 & 0.007
\end{tabular}

each $\mathrm{keV}$ setting that can be selected by the operator. The minimum value of $\mu_{L}$ was for fat $\left(0.1190 \pm 0.00680 \mathrm{~cm}^{-1}\right)$ and maximum $\mu_{L}$ was for $4 \times \mathrm{Hb}$ blood $\left(0.1449 \pm 0.00794 \mathrm{~cm}^{-1}\right)$. Relation between CT number and mean linear attenuation coefficient is shown in Figure 2. A linear regression for water, pomegranate juice (red water), milk, fat, $\mathrm{Hb}$ and $4 \times \mathrm{Hb}$ was obtained. According to present data, the difference of $\mu_{L}$ between $\mathrm{Hb}$ and $4 \times \mathrm{Hb}$ was significant $(P<0.000)$. The difference of water and pomegranate juice (red water) $\mu_{L}$ was significant with confidence greater than $95 \%$ $(P<0.000)$. Relation between energy $(\mathrm{keV})$ in tube potential of CT and linear attenuation coefficients were also studied (Figure 3). Each energy (keV) and amount of $\mu_{L}$ of water, fat, $\mathrm{Hb}$ and $4 \times \mathrm{Hb}$ showed a good differentiation according to energy range from 75-364 keV.

The energy-response of linear attenuation coefficient relationship over a wide range of energies is presented in Figure 3. The results of a experiment of $\mu_{L}$ of $4 \times \mathrm{Hb}, \mathrm{Hb}$, water and fat is plotted against the tube potential of CT; 


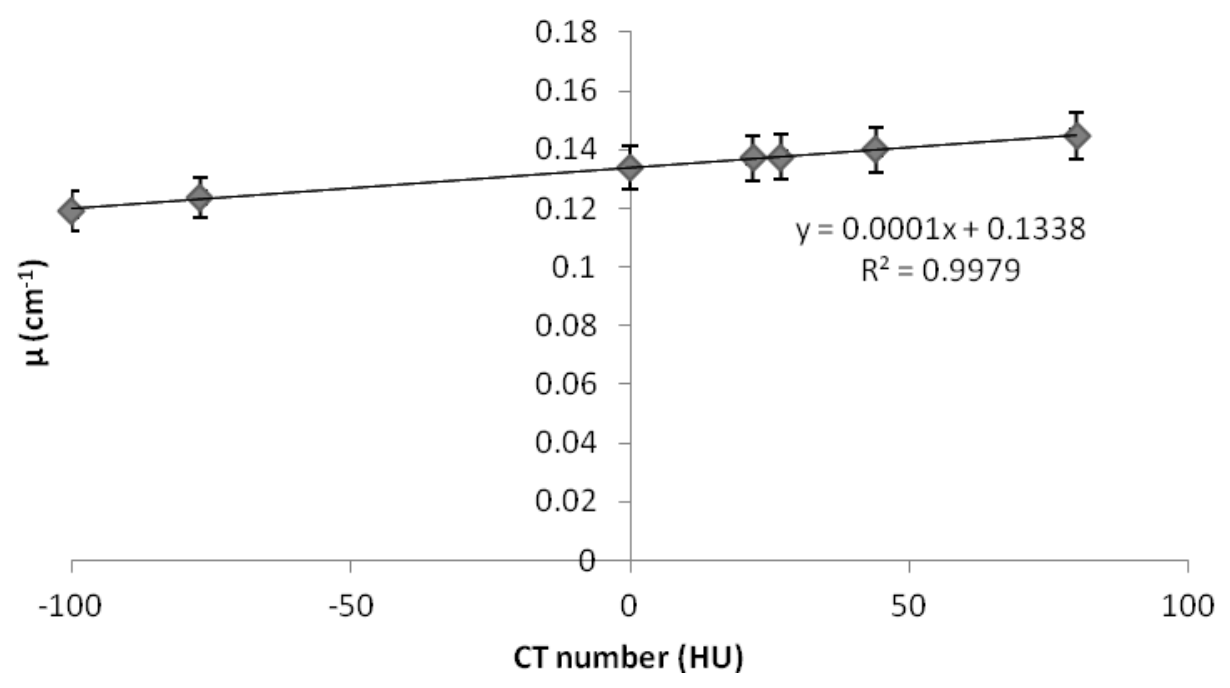

Figure 2: Relation between CT number and mean linear attenuation coefficients of seven materials used in this experiment, $y=0.000 x+0.1338 ; R^{2}=0.9979$

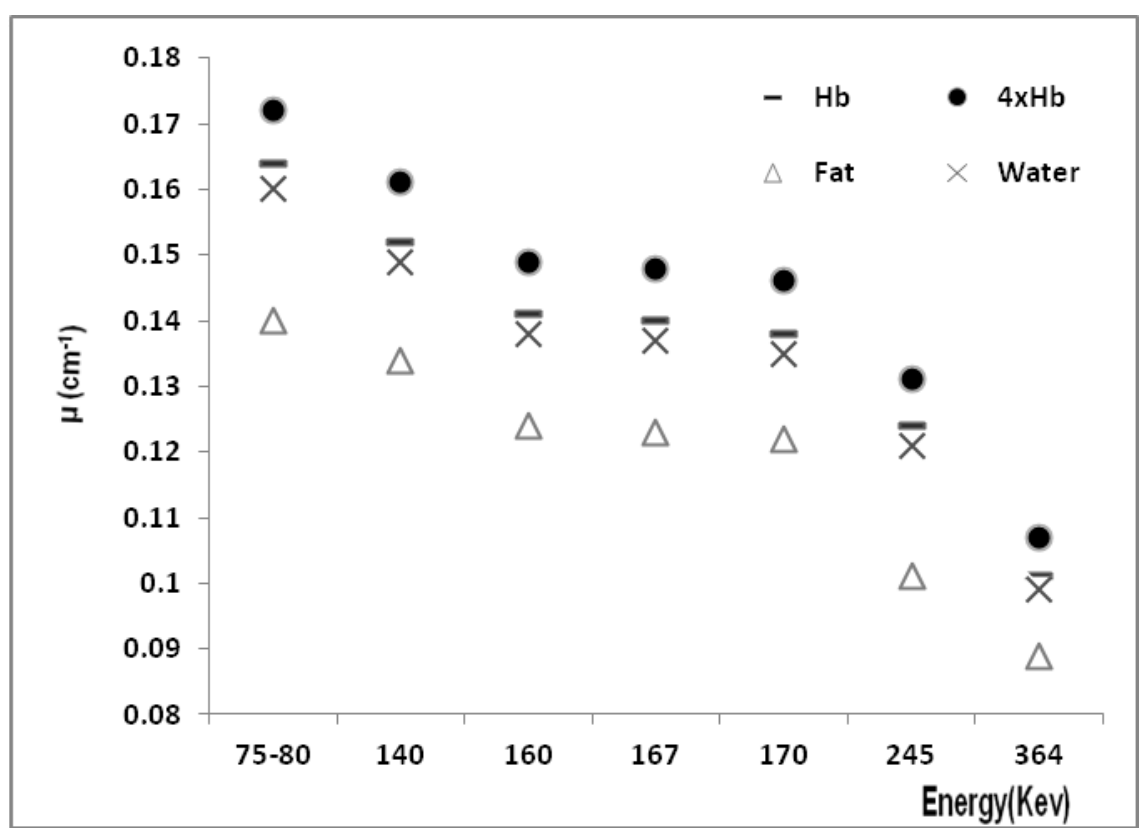

Figure 3: Distribution of linear attenuation coefficients of water, fat, hemoglobin and $4 \times$ hemoglobin according to energy range from 75 to $364 \mathrm{keV}$. 
the $\mu_{L}$ of each group decreases when energy increases, which usually occurs between 75 and $160 \mathrm{keV}$, a further increase did not change $\mu_{L}$ value, but from $170 \mathrm{keV}$, a rapid decrease of $\mu_{L}$ was observed with further increase in energy.

\section{Discussion}

The greatest difference was observed between $\mathrm{Hb}$ and $4 \times \mathrm{Hb}$ which can induce an early detection of breast cancer cells in its early stages. It means if breast cells are going to be abnormal in early stages by this method, $\mathrm{Hb}$ and $4 \times \mathrm{Hb}$ differentiations are possible. The difference of $\mu_{L}$ between $\mathrm{Hb}$ and $4 \times \mathrm{Hb}$ was significant $(P<0.000)$.

The data enable us to assess different conditions of breast especially prediction of blood hemoglobin distribution in normal and cancerous breast cells.

In malignant tumors, hemoglobin concentration is directly related to angiogenesis; this factor is required for tumor growth and metastases [13]. In tumor cells, blood hemoglobin concentration increases to two or four times more than normal blood hemoglobin. HU can be used to assess the CT density of liquid in body.

It has been reported that $\mathrm{CT}$ images accurately estimate the attenuation coefficients for soft tissue, blood and milk. Different scaling factors are required for materials with a density higher than that of water because of the increased Compton interactions resulting in more attenuation for lower density materials.

The same relation between $\mu$ mean and CT number was observed as shown in Table 1. Consequently, a linear regression was performed for mean energy in the relevant range until the best $\mathrm{R}^{2}$ and linear fit was obtained (Figure 2).

The values of the $\mu_{L}$ are not significant between $\mathrm{Hb}$ and milk $(P=0.078)$ that means this method sensitivity for healthy or normal breast cell is acceptable. The difference of $\mu_{L}$ is significant between $4 \times \mathrm{Hb}$ and milk $(P<0.000)$. It means this method sensitivity and specificity are acceptable for the comparison of $\mathrm{Hb}$, milk and $4 \times \mathrm{Hb}$ even in feeding woman.

An average $\mathrm{HU}$ value was determined for each of the materials using a $120 \mathrm{kVp}$ X-ray CT scanner [11]. The present study illustrates a comprehensive method in which HU can be derived from the grey levels of any CT machine possessing sufficient linearity. Overall, the corrected Hounsfield numbers in each of the CT acquisitions appear to be within a few percents of the predicted HU and attenuation coefficient for each material into Equation (2) at the effective energy derived by the linear regression of seven reference materials.

In the present research, the CT number of water is expected to be $0 \pm 7 \mathrm{HU}$ for images acquired at slice thickness and $\mathrm{kVp}$ setting similar to McCollough et al. [14] and CT number for Polyethylene was between -107 and -87 HU which approximates the result ( -77 and -100) HU. In a study of Brown et al. [11], Polyethylene was $2 \pm 14 \mathrm{HU}$. This variation of $\mathrm{HU}$ is perhaps induced by difference in the tube current.

Additionally, another study on normal/ healthy breast bloods showed the range of $\mathrm{HU}$ values of the serous fluids was 13-38 HU, but in the non-sediment blood changed to $40-88$ $\mathrm{HU}$ [15]. In the present study, the ranges of CT number of $\mathrm{Hb}$ and $4 \times \mathrm{Hb}$ were $22 \pm 6 \mathrm{HU}$ and $80 \pm 4 \mathrm{HU}$, respectively.

The advantage of this study is the expression of this matter that if CT number analyzing data is added to patient's CT imaging report, it will be unable to provide more information about disease status in chest CT.

Most articles were about water, fat and $\mathrm{Hb}$ (normal) but $4 \times \mathrm{Hb}$ (abnormal) and its comparison with other concentrations and liquids studied in rare cases by $\mathrm{CT}$ imaging HU.

In chest diseases i.e. lung and heart, it is possible to analyze different concentrations of hemoglobin and other fluids especially blood according to their differences in $\mathrm{CT}$ numbers. 
Moreover, the calculation of attenuation coefficient is possible for all. Another suggestion of this study is for breast feeding mothers. In these cases, the assessment of CT number of breast $\mathrm{Hb}$ in ductal diseases enables us to predict normal or abnormal breast cells.

Therefore, identification and characterization of HU of hemoglobin and main fluids in chest CT is a useful method, without more charges and radiations for patients in the prediction of cancerous breast cells.

\section{Conclusion}

The study of CT number and linear attenuation coefficient of different concentration of $\mathrm{Hb}$ provides a possibility for early predicting of breast cancerous cells existence $(4 \times \mathrm{Hb})$.

\section{Acknowledgment}

The authors would like to thank the staff of Dey Radiology Center for providing CT scanning of materials. This work is supported by Tabriz University of Medical Sciences.

\section{Conflict of Interest}

None

\section{References}

1. Matsumoto K, Jinzaki M, Tanami Y, Ueno A, Yamada M, Kuribayashi S. Virtual monochromatic spectral imaging with fast kilovoltage switching: improved image quality as compared with that obtained with conventional 120-kVp CT. Radiology. 2011;259:257-62. doi: $\quad 10.1148 /$ radiol.11100978. PubMed PMID: 21330561.

2. Rodriguez-Granillo GA, Rosales MA, Degrossi $E$, Rodriguez AE. Signal density of left ventricular myocardial segments and impact of beam hardening artifact: implications for myocardial perfusion assessment by multidetector CT coronary angiography. Int J Cardiovasc Imaging. 2010;26:345-54. doi: 10.1007/s10554-009-9531-5. PubMed PMID: 19908161.

3. Zaidi $H$, Hasegawa B. Determination of the attenuation map in emission tomography. $J$
Nucl Med. 2003;44:291-315. PubMed PMID: 12571222.

4. Roach PJ, Schembri GP, Shon IAH, Bailey EA, Bailey DL. SPECT/CT imaging using a spiral CT scanner for anatomical localization: impact on diagnostic accuracy and reporter confidence in clinical practice. Nuclear medicine communications. 2006;27:977-87. doi: 10.1097/01.mnm.0000243372.26507.e7.

5. Wang X, Meier D, Taguchi K, Wagenaar DJ, Patt BE, Frey EC. Material separation in $X-$ ray CT with energy resolved photon-counting detectors. Med Phys. 2011;38:1534-46. doi: 10.1118/1.3553401. PubMed PMID: 21520865. PubMed PMCID: 3060934.

6. Gucuk A, Uyeturk U. Usefulness of hounsfield unit and density in the assessment and treatment of urinary stones. World J Nephrol. 2014;3:282-6. doi: 10.5527/wjn.v3.i4.282. PubMed PMID: 25374823. PubMed PMCID: 4220362.

7. Churchill RJ. CT of intra-abdominal fluid collections. Radiol Clin North Am. 1989;27:65366. PubMed PMID: 2657846.

8. Allen BC, Barnhart $H$, Bashir M, Nieman C, Breault S, Jaffe TA. Diagnostic accuracy of intra-abdominal fluid collection characterization in the era of multidetector computed tomography. Am Surg. 2012;78:185-9. PubMed PMID: 22369827.

9. Bydder GM, Kreel L. Attenuation values of fluid collections within the abdomen. J Comput Assist Tomogr. 1980;4:145-50. doi: 10.1097/00004728-198004000-00002. PubMed PMID: 7365010.

10. Huda W, Slone RM. Review of radiologic physics. Philadelphia: Lippincott Williams \& Wilkins; 2003.

11.Brown S, Bailey DL, Willowson K, Baldock C. Investigation of the relationship between linear attenuation coefficients and CT Hounsfield units using radionuclides for SPECT. Appl Radiat Isot. 2008;66:1206-12. doi: 10.1016/j.apradiso.2008.01.002. PubMed PMID: 18662614.

12.Campos MJ, De Souza TS, Mota Junior SL, Fraga MR, Vitral RW. Bone mineral density in cone beam computed tomography: Only a few shades of gray. World J Radiol. 2014;6:607-12. doi: 10.4329/wjr.v6.i8.607. 
Mehnati P., Jafari Tirtash M., Ghavami M.

PubMed PMID: 25170398. PubMed PMCID: 4147441.

13.Rice A, Quinn CM. Angiogenesis, thrombospondin, and ductal carcinoma in situ of the breast. J Clin Pathol. 2002;55:569-74. doi: 10.1136/jcp.55.8.569. PubMed PMID: 12147647. PubMed PMCID: 1769713.

14.McCollough $\mathrm{CH}$, Bruesewitz MR, McNitt-Gray MF, Bush K, Ruckdeschel T, Payne JT, et al. The phantom portion of the American College of Radiology (ACR) computed tomography (CT) accreditation program: practical tips, artifact examples, and pitfalls to avoid. Med Phys. 2004;31:2423-42. doi: 10.1118/1.1769632. PubMed PMID: 15487722.

15.Zech WD, Jackowski C, Buetikofer Y, Kara L. Characterization and differentiation of body fluids, putrefaction fluid, and blood using Hounsfield unit in postmortem CT. Int $\mathrm{J} \mathrm{Le}$ gal Med. 2014;128:795-802. doi: 10.1007/ s00414-014-1030-0. PubMed PMID: 24903128. 